\title{
Digital Social Media: An Interactive Technology Incorporated as a Competitive Advantage for Business
}

\author{
http://dx.doi.org/10.3991/ijim.v8i2.3576 \\ P. A. Correia Pereira ${ }^{1}$ and I. García Medina ${ }^{2}$ \\ ${ }^{1}$ University of Vic, Barcelona, Spain \\ ${ }^{2}$ Glasgow Caledonian University, Glasgow, UK
}

\begin{abstract}
In a more transparent and dynamic world, in which consumers trust other consumers more for advice and recommendations on products and services, the continuity of organizations appears to be associated with socialization, the sharing of interests and the interaction with the audience. This is associated with the incorporation of digital technologies to business, specifically the use of social media.
\end{abstract}

Consequently, it is timely and interesting to explore the phenomenon of virtual socialization, although it is a littlestudied field and what is needed is an innovative and theoretical approach based upon theories of marketing and communication. Expertise in these areas is present in all organizations and their performance is important for appropriate development of them.

This work is a qualitative analysis about the behavior, reactions and attitudes of individuals to organizations, in order to understand the social factors that contribute to sustainable competitive advantages of organizations which can support strategic and future actions.

We conclude that relevant factors associated with the tacit knowledge of the organization, specifically to learning and social interaction of the organization and their knowledge of virtual communities. The higher the coexistence of factors, the more difficult is the replication and greater will be the hypothesis of sustainable competitive advantage.

Index Terms- Social Networks, Digital Communication, eMarketing.

\section{THE IMPORTANCE OF SOCIAL MEDIA FOR DIGITAL MARKETING COMMUNICATION}

The reinvention of society and the modern organizations due to the digital influences have been called by several authors with different designations like Wikinomics [21], said:, Groundswell [11], Tribes [6], among others. Call to the whole movement mass collaborations, social networks, social networking or social media, and are mainly characterized by the speed, transparency, collaboration, trust, ubiquitous, and socially. The idea is to bring people together in a single environment, a large brain with direct connections (producer-consumer).

Social media have revolutionized the way people communicate and share information between each other. The consolidation of social media on a daily basis is increas- ingly intense, although some cases have been highlighted, in particular Facebook.

According Reference [7], "The advantage of the competitiveness comes from a technological introduction and the constant adaptation along the time to the technological evolution inserted in the strategy of the organization."

But technology alone can hardly provide a sustainable competitive advantage to business, the value comes from the sphere of innovation and business structural changes (new business models, process changes,...) and the product / service [14].

Reference [17] said: "the phenomenon has changed social behaviors and captivated new users, especially in female and senior citizens, who did not use information technologies as much before pre social media when users were overwhelmingly male." With the emergence of social networks these audiences have developed a greater affinity with digital technologies, having a regular and dynamic coexistence in the virtual world, occupying a prominent place in virtual social interactivity. The participation on a massive scale of thousands of people throughout the world to the phenomenon of social media has contributed to the exponential growth of the various social networks, allowing them to achieve the critical mass necessary for the social media to become an appreciated channel of communication for many organizations.

The use of the online phenomenon by organizations involves developing a communication program of integrated marketing, maximizing the individual and collective contribution of all activities of communication, defining for the virtual channels a more personal program of communication in the field of direct and interactive marketing [19].

This will make it possible to perceive the role of the communicational marketing in the creation of content and interaction with customers in the various social platforms such as Facebook, Twitter, Linkedin, Youtube, MySpace, Orkut, blogs and other social networks [19].

Reference [22] state that digital social networks are the amplifier of internal capabilities of the organization at the level of behavior and technology. To use "outsourcing" for the management of social networks is a strategy ready to fail because it transposes to third parties what should be the essence of the organization in the creation of competitive advantages to perceive and relate to its target audience. Embarking on interactive marketing in social networks, is not just one more option for communication 
with customers by copying the actions of the competition. It consists of a deep change in the behavior in the organization. Only the experience and the corresponding temporal allocation will lead to interactions of a high level that allow the individual consumer to create unique experiences with the company and it will become the key to new sources of competitiveness.

An approach to transparency and trust concentrates the whole organization, and is an integral part of the activities of management, in particular in the perception of the internal and external environment, the vision and mission, defining and implementing strategies and monitoring. The growing importance of social media as a tool of marketing-mix, has encouraged the expansion of similar technologies, new and powerful on-line applications are to be launched especially in the mobile channel, which will be the main form of access to social networks in the near future, mobility will be driven by devices such as smartphone, e- readers and tablets.

According reference [17]: "the ubiquity of the technology, inherent characteristic of the new tools, the communication between devices, connectivity and the convergence of technologies of information associated with georeferenced location, will contribute to a most enriching experience of the user."

Reference [3] state that "the visibility and convergence are moving to a new era of greater transparency and commitment in the relationships individual - individual and individual - organization". However, the majority of them are still linked to the ranking of their profiles, "how many friends I have in my profile", "who said I like? ", as if that resembled the popularity or fame, how important is this information that is worth as much as the hits of the site in the process of compromising between both sides.

\section{SOCIAL MEDIA MARKETING COMMUNICATION STRATEGIES}

While the practice of management may not be evolving as fast as it once did, the environment that faces 21 st century businesses is more volatile than ever. This new century may still be young, but it has already spawned a sizable brood of daunting managers' challenges that are markedly different from the ones that taxes our forebears; the new reality calls for new organizational and managerial capabilities. To thrive in an increasingly disruptive world, companies must become as strategically adaptable as they are operationally efficient. To safeguard their margins, they must become gushers of rule-breaking innovation [7].

The strategic basis for social media is centered in real relationship with people and on the need to eliminate the noise created by the rankings, find out what is important in long-term relationships between the organization and its fans and focus on genuine relationships, honest, lasting and value to both understand who is interested in maintaining a relationship with us and is truly on and react to our presence and actions.

Important contacts are those with whom we have a relationship of proximity and interactivity that allows the exchange of views and discussions on common interests, people who actively participate with their opinion on the subject, people who talk about winter sports because they have passion, compliment or criticize you because they live in this community. People are connected by real things and matters of mutual interest rather than rankings.
The difference is about people feeling essential to the relationship. Consequently, "networking" is important when there is a real link for everyone and is a useless distraction when the real connection does not exist, although we are constantly seduced by the image of useless popularity based on the numbers, it is important to know who follows my path and what I would follow them and go after these people and get the privilege of one day be able to gain value from this relationship [19].

Therefore, marketing in social media is not "speak loud" ads to people, but to lead, to do something that captivate, connect people who are interested in a connection with a mutual order. People want to follow someone who is genuine and authentic.

For reference [11] the strategic plan of social media establishes four procedural steps: people (who are the customers and for what they are prepared?), goals (interact in the media in the marketing area or sales grow, internal participation), strategy (what is the relationship with customers? use customers to spread the company message in the market?), technology (what are the applications to use, blogs, wikis, social networking?).

The objectives of the strategic plan are to enable the consumer to identify the existence of the company (company and products / services), differentiate from the competition, being a reference in the labor market and have the preference of consumers (be valuable throughout time), [19].

Create and implement a social strategy is difficult, mainly because there are few precedents and models to follow, so it is necessary to be constantly aware of the challenges and prepare to solve them [11]. Without a comparative basis, experimental models are predominant; however, make multiple errors in the field of social media is by far desirable than be inactive, is the world of the social economy [17], [21].

Certainly, the implementation of a strategy by an organization for social media will drastically alter the way business is conducted [1]. This is the adaptation to a new world, where the influence of relationships and search engine optimization are important and news are spread to all the word very quickly [19].

\section{SOCIAL MEDIA MANAGEMENT - THE ROLE OF COMMUNITY MANAGER}

The bidirectional communication management in online communities and the marketing activities of the organization are maximized by allocating specific resources to these functions, however, the allocation of responsibilities for managing social media to the Community Manager, is an issue that is not consensual and that is being debated, so there are different views and positions and various denominations. Its role is to build, manage and grow online communities around a brand.

In summary the role of the Community Manager resembles to a television debate mediator which manages the speaking time of the participants, the issues under discussion and the argument avoiding conflicts. In social networks this role is more comprehensive, it is assumed to be an advocate for community members, sponsor / supporter of the brand, making sure that the discussion is productive and positive and avoiding negative / prejudice discussions. 
The Community Manager provides customer support, responding to questions and doubts, monitors the web to find out what is being said about the company and its products / services and acts as an ambassador for the company.

Following this perspective, the manager must try to understand the participants in online communities, how they use social media, how to look for information about products or topics of interest and answers to their questions. The frequent social networking monitoring allow the Community Manager to observe these attitudes, perceived regularity, with the intention of predict personalities and behaviors of the participants in the social network about the company, its products and services and lead members community in the right direction, keeping a positive conversation about a common interest, so as to ensure that members have an interaction valued by both.

Therefore, the Community Manager must ensure bidirectional communication, ensuring that members provide feedback while the brand keeps them updated, ensures that both members and managers learn the most of each other, and that they pay attention to their role in the company, its responsibilities and objectives and be connected to the various departments of the company, especially to marketing, to customer service and administration. The definition is not accurate, due to the multiple tasks involved, sometimes be defending the client but cannot deny their brand loyalty [13].

\section{BE SUSTAINABLE}

The effective use of social media can be a source of competitive advantage for organizations, difficult to replicate by others, due to the connection architecture to the company itself, occupying a strategic role at the level of differentiation or cost, instead of a merely presence role. Answering to what have company to offer that is unique and valuable to current and potential customers?

The strategic sustainability of organizations for social networks lies in an ongoing analysis of the behavior of individuals and their needs and desires.

The suitability of products and services to the needs and desires of consumers are a constant challenge for any organization. The current media ecosystem transformations are aspects that should be analyzed from the synchronization perspective between the organization and consumers.

To obtain a competitive advantage, it is necessary to carry out business activities better than competitors, then, the competitive advantage is synonymous of a superior performance. The differences in how firms choose or execute strategic activities are the basis of competitive advantage [2].

A company gets a sustainable competitive advantage when implementing a major strategy followed and implemented by few opponents simultaneously, and they have difficulties in acquiring the necessary resources to implement it. A company gets a temporary competitive advantage when implementing a major strategy, followed by some opponents, and they do not have significant difficulties in acquiring the necessary resources to implement that strategy. A company faces constant competition, when implementing an important strategy that is simultaneously implemented by several opponents. A company is in a competitive disadvantage when implementing a strategy that is not important, so it does not reduce costs or increase profits [12].

\section{UNDERSTAND THE LOCAL SOCIAL MEDIA MOVEMENT}

Although we live in a worldwide economy it is interesting to know how local economies are adjusting to the global social media phenomenon.

The overall studies of marketing communication on the subject of social media are relatively recent, but this does not mean that are not relevant, as Kelsey said: "Internet is a really powerful and inexpensive channel for communication, distribution and sales". Also reference [18] explains that before the web, companies used the media only for promotion, but with the Internet, companies use the media to develop relationships with customers.

The problem is that it is necessary to know how to use digital social media and how to manage the customer relationship in order to take advantage of them and before to arrive to this stage it is necessary to know the publics.

During the four months period between October 2011 and January 2012, 150 individuals and 15 companies were analyzed in Funchal and Lisbon (Portugal). To have the perception of knowledge degree about social networks in particular on Facebook and why people participate in the network and adhere to brand pages.

Understand the strategic vision of those responsible for company's marketing and communication about Facebook. Analyze the role of Facebook in marketing activities and interactive communication (users and companies). The contribution of Facebook for marketing and communication actions. (Competitive advantages and contribution to brand loyalty). Which in this case, are related with the integration of social networking on marketing communication to obtain sustainable competitive advantages.

Although the evolution of information technology is a catalyst for a more intense online social experience, it is important to understand how to live the virtual experience and how evolve the communication between individuals and companies (how to adapt to this new consumer audience), face the current short term models based on offline actions, reactive strategic actions, miss perception of users, lack of information on social network consumers' life.

Despite the recognized importance of social media for marketers, few companies are prepared to manage this change.

In most cases there is not a social network integration in the company activities in all departments and workers, as well as viral marketing planned actions, models and platforms for analysis and monitoring of companies participation in the network (except the monitoring actions allowed by Facebook), which enable to measure the impact of social media strategies in business, creating new assets as "crowdsourcing" (to use volunteers and collective knowledge of the Internet to solve problems, create content and solutions).

Today the focus continues to be very connected to sales and promotions and to traditional communication channels when it should move to create interactions with meaning for the audience through content before focusing on sales. 


\section{CONSIDERATIONS AND FINDINGS}

The reinvention of societies and organizations is shown to be connected to the social essence of human motivation and the evolution of the specie, which is a reflection of the agglomeration of individual behavior in society.

Meeting the needs of social connection has allowed technological tools related to social networks to have a very high degree of adhesion in a short period of time.

Social networks are a new marketing tool that are more specific than digital marketing and which go beyond communication with a philosophy shared by all organizations in their actions and reactions, which connect all departments and employees.

Understanding which factors are relevant for the communication between companies and consumers in the social networking phenomenon is essential to define the company future.

The main reason for participation in social networking is social communication but there are other interests, related with the companies, their products and services. Users become "fans" of theirs pages, read, comment and interact, it further points out with "likes" the published content, and have a predilection for frequent communication. For users, the company's presence in the social network is an important factor in reputation.

The use of social networks as a means of communication to integrate multiple communication tools are confirmed by individual users but only a minority of companies representatives users feel that Facebook integrates with other tools.

The emergence of social networks and the concentration of various communication tools into a single platform have captivated individual users and have revolutionized the way people communicate and share information. However, this has not been identified as a purely technological change but above all as a cultural one. It is a process of social transformation where technology is an inseparable element of social and cultural trends. For businesses, the adoption of social networks has not been as significant as it still has a traditional view of business involvement in social networks. They see it as a push communication in detriment of the interactivity that this channel requires its participants.

The strategic vision of those responsible for marketing and communication on the social network Facebook is a new way of communication is enforced through the realtime electronic dialogue. Companies consider social media as a key element of their marketing strategy and not just as a channel of their traditional communications strategies (although there are some differences in the social network participation which are related with the company size). In addition, sharing information interactively with clients could hardly be done through traditional channels. This bidirectional communication management is a key success factor of this type of communication strategies. Before the advent of social networks, organizational communication was traditionally characterized as unidirectional, the company transmitted the message and the audience was limited to hear it without having the option to respond, allowing the organization to control the message.

The bidirectionality between the company and fans is also a way to segment marketing activities and communi- cation, a source of information about needs and desires. The fact that the company maintains a stable relationship with the "fans" results in increased brand loyalty.

The evidence continues to show us the fact that companies will pass through the biggest change of their short history. The models of network collaboration and innovation can provide to managers with new possibilities to arouse the human potential, whose success is in challenging the knowledge / experience that companies accumulated over several years of thought.

In recent years, the practice of marketing an expansion of his coverage has been verified, thus amplifying the transaction connected with the interactive relations. The basic objective of trade relations goes beyond the transaction also includes the development of stable and lasting relationships with users, which are beneficial to both parties, leading to increased confidence and consequently the willingness to help each other, reflecting directly in reducing the costs and the realization time of transactions.

Organizational survival increasingly depends upon socialization, sharing interests and activities with the audience linked to the incorporation of digital technologies in their activities, especially those related to social networks. Technology emerges as a support for the satisfaction of social connection, transforming communication between people and companies, making it much more dynamic and transparent.

Facebook stands out for its size and orientation to relationships, within social networks Facebook is dominant. It is an emerging area of convergence of the pre-existing communication media, heterogeneous collaborative cultures and participatory audiences.

However, the adoption of Facebook technology is not sufficient for the integration in the online social movement, as the technology of Facebook and digital marketing themselves do not constitute a competitive advantage, it depends on the ability of the company to look for opportunities in your market, how they integrate them into routines and management capacity of the organization. It implies a strategic approach to monitoring consumer behavior and detection of their needs and desires by the company.

Non-Facebook participants who observe this phenomenon and its view of future participation indicate that most have no intention of using Facebook in the near future because they are not interested. This means that companies have to simultaneously maintain the traditional channels because there is a part of the public/consumer still remains outside of social networks.

As we have seen, there are many positive factors associated with the participation in the social network. Interactivity, the detection of customer needs, adjustment of supply, transmission of content without geographical boundaries and ease of implementation of viral marketing campaigns are the most import of these factors.

Concerning the less positive factors of social network participation, we could mention the importance of the lack of credibility of some information, the excess of information, the lack of response from some brands and delay in responding to customer requests.

Finally, it is important to note that monitoring and learning through experience in the network as part of culture and organizational routines are specific factors that 
may become a competitive advantage by being relevant factors associated with tacit knowledge of the organization.

\section{CONCLUSIONS}

The physical and digital worlds are becoming increasingly linked, socialization and human relations decreases their physical dependence on connecting people around the world from different ethnicities and beliefs, a result of increased connectivity and convergence of information and mobile technologies, allowing to be online regardless of geographic location and therefore to act and to have access to information on social networks in real time.

Many companies start realizing that the number of fans on their pages is not synonymous with success in social media, the value is not the number of fans in their communities but the compromise between people and the company increased by social networks. Consumers are no longer passive, they are taking an active role in organizational communication, so organizations need to adopt a culture of inter-relational customers, based on trust and transparency, the numbers will come as a result of this work, but if companies have no idea of this relationship, they do not know what they are doing in social networks.

There is a progression in the development of standards of transparency on-line. Consumers will manage and share their data with trading partners, making it a viable business model.

The major social players (Amazon, Google, Facebook) accumulate individualized information about each of their users in four groups of variables of marketing segmentation: demographic, geographic, psychographic and behavioral. In order to optimize the selection and provision of information customized to the individual profile, this customization can be extended to other areas of business and other businesses cut superfluous information received by consumers, which increase the efficiency and effectiveness of traditional marketing to social media.

New applications for the various social and mobile platforms will tend to a high customization, increasing the link between organizations and customers, this will provide increased communication effectiveness of on-line advertising with a social and interactive nature of the online marketing, viral and "worth of mouth" with a growing consumer participation in organizational communication. Obviously, collaborators need to get used to working in a wider and more dynamic community.

\section{REFERENCES}

[1] Brown, E., (2010). Working the crowd, social media marketing for business. British Informatics Society Limited. Swindon.

[2] Davis, L., Dehning, B. \&Stratopoulos, T., (2003). Does the market recognize IT-enabled competitive advantage? Information \& Management 40, 705-716. http://dx.doi.org/10.1016/S03787206(02)00092-7

[3] Dunay, P \& Krueger, R. (2010), Facebook marketing for dummies, Wiley Publishing, Inc.
[4] Godin, S., (2007). Permission marketing: turning strangers into friends and friends into customers. Pocket Books, Simon \& Schuster UK Ltd.

[5] Godin, S., (2009). All marketers are liars: The power of telling authentic stories in a low-trust world. Penguin Group.

[6] Godin, S., (2010). Linchpin: Are you indispensable? How to drive your career and create a remarkable future. Piatkus Books.

[7] Hamel, G., (2007). The future of management. Harvard Business School Press.

[8] Kelsey, T., (2010). Social networking spaces, from Facebook to twitter and everything in between, Apress.

[9] Kotler, P., Kartajaya, H. \&Setiawan, I., (2010). Marketing 3.0: from products to customers to the human spirit. John Wiley \& Sons. http://dx.doi.org/10.1002/9781118257883

[10] Kotler, P., Keller, K., Brady, M., Goodman, M. \& Hansen, T. (2009). Marketing management. Pearson Education Limited.

[11] Li, C. \&Bernoff, J., (2011) Groundswell: Winning in a world transformed by social technologies. Harvard Business School Press.

[12] Mata, F., Fuerst, W. \& Barney, J., (1995). Information technology and sustained competitive advantage: A Resource-Based analysis. MIS Quarterly/December, 487-505. http://dx.doi.org/10.2307/ 249630

[13] Ng, De., (2011). Online community management for dummies (For Dummies (Computers)). John Wiley \& Sons. New Jersey.

[14] Peppard, J. \& Ward, J., (2004). Beyond strategic information systems: Towards an IS capability. Journal of Strategic Information Systems, 13, 167-194. http://dx.doi.org/10.1016/ j.jsis.2004.02.002

[15] Peppard, J. \& Ward, J., (2005). Unlocking sustained business value from IT investments. California Management Review, 48, 52-70. http://dx.doi.org/10.2307/41166327

[16] Peppard, J., Lambert, R. \& Edwards, C., (2000). Whose job is it anyway? Organizational information competencies for value creation. Information Systems Journal, 10, 291-322. http://dx.doi.org/10.1046/j.1365-2575.2000.00089.x

[17] Qualman, E., (2009). Socialnomics: How social media transforms the way we live and do business. Wiley Publishing, Inc.

[18] Schubert, P. \& Leimstoll, U., (2007). Importance and use of information technology in small and medium-sized companies, Electronic Markets, 17, 38 -55. http://dx.doi.org/10.1080/10196 $\underline{780601136799}$

[19] Scott, D. (2010). The new rules of marketing and PR. John Wiley \& Sons, Inc..

[20] Scott, D. (2011). The new rules of marketing \& PR: How to use social media, online video, mobile applications, blogs, news releases, and viral marketing to reach buyers \& PR: how to use social media, blogs. John Wiley \& Sons; 3rd Edition.

[21] Tapscott, D., \& Williams, A., (2008). Wikinomics: How mass collaboration changes everything. Atlantic Books.

[22] Wilson, H., Guinan, P., Parise, S. \& Weinberg, B., What's Your Social Media Strategy? USA: Harvard Business Review. Vol.89, n. 7/8, 2011.

\section{AUTHORS}

P. A. Correia Pereira, is with the University of Vic, Sagrada Familia, 7, 08500 Barcelona, Spain (e-mail: pacorreia4@gmail.com).

I. García Medina is with the Glasgow Caledonian University, Cowcaddens Rd, Glasgow, Lanarkshire G4 0BA, UK (e-mail: irene.Garcia2@gcu.ac.uk)

Submitted, February, 17, 2014. Published as re-submitted by the authors April 05, 2014.. 